\title{
Fat Tails and the Social Cost of Carbon
}

\section{Citation}

Weitzman, Martin L. 2014. Fat Tails and the Social Cost of Carbon. American Economic Review 104, no. 5: 544-546.

\section{Published Version}

doi:10.1257/aer.104.5.544

\section{Permanent link}

http://nrs.harvard.edu/urn-3:HUL.InstRepos:12992320

\section{Terms of Use}

This article was downloaded from Harvard University's DASH repository, and is made available under the terms and conditions applicable to Other Posted Material, as set forth at http:// nrs.harvard.edu/urn-3:HUL.InstRepos:dash.current.terms-of-use\#LAA

\section{Share Your Story}

The Harvard community has made this article openly available.

Please share how this access benefits you. Submit a story.

Accessibility 


\title{
Fat Tails and the Social Cost of Carbon
}

\author{
By Martin L. WeitzMan*
}

At high enough greenhouse gas (GHG) concentrations, climate change might conceivably cause catastrophic damages with small but nonnegligible probabilities. Other things being equal, this should lower the discount rate used to evaluate mitigation-investment decisions and raise the social cost of carbon (SCC). If the bad tail of climate damages is sufficiently fat with probability, and if the utility function has relative risk aversion greater than one, then (at least in theory for at least some formulations) this insurance-like catastrophe-reducing aspect of mitigation investments can be very powerful. In the most extreme limit this tail-hedge insurance effect can be infinitely strong and can dominate the economic analysis by making the SCC infinite. This kind of extreme (and empirically unbelievable) limiting result is a version of what I have previously labeled the "dismal theorem.".

In this paper I use the simplest possible model to lay bare the basic structure of the argument. I then attempt to place the underlying issues in a balanced perspective. The "dismal theorem" of an infinite SCC is a theoretical limiting result, which relies on particular assumptions that may or may not have actual relevance for climatechange policy depending upon the interaction of a variety of empirical factors, functional forms, and parameter values. I argue that the main value of the "dismal theorem" is to serve as a warning flag that a credible economic analysis of climate change should seriously consider extreme tail values of damages and their associated probabilities because they may have the potential to increase the SCC significantly.

\footnotetext{
* Economics Department, Harvard University, Littauer Center, Cambridge, MA 02138 (e-mail: mweitzman@harvard.edu).

${ }^{\dagger} \mathrm{Go}$ to http://dx.doi.org/10.1257/aer.104.5.544 to visit the article page for additional materials and author disclosure statement(s).

${ }^{1}$ See Weitzman $(2009,2011)$.
}

\section{A Super-Simple Expository Model}

The simplistic model here has two periods. Some base case of abatement strategy is given. All consumption refers to "effective consumption"-after climate change damages have been subtracted. The utility of consumption is $U(C)$. Present consumption is $C_{0}$. Future consumption is the random variable $\tilde{C}$, whose expected utility is discounted by $\beta$. Welfare is $W=U\left(C_{0}\right)+\beta E[U(\tilde{C})]$, where $E$ is the expectation operator. Let $\underline{C}$ represent a catastrophic low value of effective consumption that occurs with probability $p$, where both $\underline{C}$ and $p$ are considered to be "very small."

Suppose that one extra unit of carbon abatement uniformly shifts upwards future consumption by the multiplicative factor $\theta>0$. (This is consistent with having a multiplicative damages function.) For utmost simplicity, I now analyze only the effect upon the catastrophe outcome, which is the main focus of attention for this paper. The effect is that with probability $p$ the postabatement level of catastrophic consumption is now $(1+\theta) \underline{C}$, instead of the preabatement level of $\underline{C}$. Abatement here induces first-order stochastic dominance via an upward shift in the probability- $p$ point mass: $\underline{C} \rightarrow(1+\theta) \underline{C}$.

The social cost of carbon (SCC) is the (negative of the) change in $C_{0}$ per small change in abatement that would give the same level of welfare $W$ as before. In words, it is the willingness to pay for a small extra unit of abatement. ${ }^{2}$ Assume utility is of the CRRA form $U(C)$ $=C^{1-\eta} /(1-\eta)$, where the coefficient of relative risk aversion is $\eta>1$. Normalize $C_{0}=1$. With this specification, the $S C C$ here is readily calculated to be

$$
S C C=\beta \theta\left[p \underline{C}^{1-\eta}\right] .
$$

\footnotetext{
${ }^{2} \mathrm{~A}$ procedure for empirically deriving the SCC is described, e.g., in Greenstone, Kopits, and Wolverton (2013).
} 
I want to analyze the extreme case of a very rare, very catastrophic climate event where simultaneously $p$ and $C$ are both very small. Several observers have expressed the belief that an essential ingredient in a cost-benefit analysis of climate change is the potential for a small-probability high-impact disastrous outcome. ${ }^{3} \mathrm{I}$ think it is at least interesting, and may perhaps give some useful insights, to investigate, in the spirit of a kind of "stress test" of the model, what happens to the SCC of formula (1) in the most extreme limit as simultaneously $p \rightarrow 0$ and $\underline{C} \rightarrow 0$.

To get a handle on this limiting issue and relate it to the tail fatness of a particular distribution, let us take $x=-\ln C$ as a measure of how deep into the bad tail we are. Let $p(x)$ be the probability of $x$. The change of variables from $\underline{C}$ to $x$ allows a convenient conceptualization in terms of the fatness or thinness of the probability tails of $p(x)$. With $\underline{C}(x)=\exp (-x)$, formula $(1)$ becomes

$$
\operatorname{SCC}(x)=\beta \theta[p(x) \exp ((\eta-1) x)] .
$$

What happens to $\operatorname{SCC}(x)$ as $x \rightarrow \infty$ ? The outcome depends on how fast $p(x) \rightarrow 0$ as $x \rightarrow \infty$. If the probability $p(x)$ declines in $x$ faster than exponentially (like the normal distribution), then (abusing terminology) $p(x)$ is thin tailed and $S C C(x)$ in (2) goes to some finite limit as $x \rightarrow \infty$. This is the kind of situation that can justify a "value at risk" type calculation that would cut off the distribution for some large $\bar{x}$ (or, equivalently, small $p(\bar{x}))$ and ignore what is in the bad tail for values $x>\bar{x}$. But what happens if $p(x)$ declines in $x$ relatively slowly? Suppose (again abusing terminology) that the probability distribution $p(x)$ is fat tailed, meaning that $p(x) \rightarrow 0$ polynomially as $x \rightarrow \infty$ (like the Student- $t$ distribution). Then $S C C(x)$ in formula (2) explodes as $x \rightarrow \infty$, and a "value at risk" type cut off of the bad tail is not legitimate. I investigate this unusual and artificial situation in the next section.

\section{A "Dismal Theorem"}

Suppose that for large $x$ the probability $p(x)$ is polynomial, meaning (for large $x$ ) that

\footnotetext{
${ }^{3}$ See, e.g., Barro (2013); Litterman (2013); Pindyck (2013).
}

$p(x) \propto x^{-\alpha}$, where $\alpha>0$. (This is the prototypical example of the relatively slow asymptotic probability convergence to zero that describes a fat tail.) Then, under the assumptions of the model, we have the following result.

$$
\lim _{x \rightarrow \infty} \operatorname{SCC}(x)=\infty
$$

I will call (3) (a form of) the "dismal theorem." Let us immediately emphasize that which is immediately obvious. The "dismal theorem" is an absurd result! It cannot be the case that society would pay an infinite amount to abate one unit of carbon. Something must be very wrong in the formulation of the underlying model.

Several things could be seriously wrong with the underlying formulation. $\left.\right|^{4}$ The limiting probabilities might not be fat-tailed in the exact and demanding sense of this model. The CRRA utility function might be inapplicable, at least in the limiting range of infinitesimal consumption where it yields an unboundedly low value. The catastrophic realizations of ever-larger $x$ might be occurring in the ever-more-distant future, so that in formula (2) one has to take a double limit as $\beta \rightarrow 0$ and $x \rightarrow \infty$. There might be something fundamentally wrong with applying the expected present discounted utility framework to such an extreme problem. I refrain from listing other possibilities. There are more than enough plausible arguments to explain away the infinity in the "dismal theorem" result (3).

Formally, it is not difficult to get rid of the infinity symbol in equation (3). One easy way is to not allow the limit in (3) to occur simply by fixing $x$ at some finite value $x=\bar{x}<\infty$. This is analogous to what "value at risk" cut offs of the bad tail attempt to do. But if $p(x)$ represents a fat-tailed slowly converging polynomial distribution, then $\operatorname{SCC}(\bar{x})$ will be sensitive to $\bar{x}$, which is not a fully comfortable resolution.

Why might $p(x)$ have a fat-tailed slowly converging polynomial form? I do not have a good answer to this important question. We have very little idea about the relevant probability distribution for the bad tail of extreme catastrophic damages at high levels of GHG concentrations. I think

\footnotetext{
${ }^{4}$ See Millner (2013) for an enumeration and evaluation of various complaints against the "dismal theorem" that have appeared in the literature. Millner concludes with his own overall assessment, which I think is fair.
} 
it is enough justification to simply say that we would like to do a stress test to make us aware of the theoretical consequences of fat tails, leaving in temporary abeyance the empirical relevance.

I wish I could report decisive convincing numerical results from modeling catastrophic climate change. Alas, and not surprisingly, any such results depend on the particular specifications going into a particular integrated assessment model. To get catastrophic climate change to matter for policy depends on some combination of a high-enough probability of occurrence, a highenough level of catastrophic damages, strongenough tail hedging, a high-enough level of risk aversion, low-enough time discounting, and several other features. Some researchers have found significant tail effects under some seemingly plausible specifications. I think the summary of Dietz (2011) is fair: "To what extent does economic analysis of climate change depend on low-probability high-impact events? The short answer is a great deal, but not to the exclusion of other factors that we already know to be very important..."

\section{Conclusion: Fat Tail as Cautionary Tale}

If the "dismal theorem" is a reductio ad absurdum, what are we left with?

An investment in abatement is shifting upward the probability distribution of effective consumption. Instead of $\tilde{C}=C$ with probability $p$, a small unitinvestmentinabatementmakes $\tilde{C}=(1+\theta) \underline{C}$ with probability $p$. In other words, the decrease in damages from an abatement investment is equivalent to first-order stochastic dominance in the distribution of consumption. How much is first-order stochastic dominance in consumption worth? Potentially quite a lot if $\underline{C}$ is catastrophically low with a "fat" probability, because it pulls us away from the terrible tail with its terrible consequences. Abatement in this case represents a valuable tail-hedge insurance investment that shows itself in a high SCC.

Since the conditions for the "dismal theorem" to hold are unusual and open to legitimate criticisms, it cannot possibly trump all other considerations. Whether some modified version of the "dismal theorem" is relevant or not is ultimately an empirical question. Unfortunately, it is an empirical question that depends on probability assumptions about extreme tail behavior, which are very difficult to resolve because we know hardly anything about extreme tail probabilities. The nature of tail events is that we have little past experience with them, and besides, climate change is a unique one-off event. This is a basic dilemma for climate change. Fat tails may be important, but how can we know their relative fatness and the tail-hedging effect of reducing extreme damages from a given climate-change investment?

The "dismal theorem" is best understood as a cautionary tale. A fat tail for rare disasters has the potential to dominate economic calculations like the SCC. Therefore, analysis of a situation that might potentially be catastrophic cannot afford to ignore tail behavior. It is not enough in such situations to look just at measures of central tendency or even just at thin-tailed probability distributions. Ignorance of the potential fatness of an extreme bad tail is not an excuse for ignoring the potential fatness of an extreme bad tail. This warning is the main message of the "dismal theorem."

\section{REFERENCES}

Barro, Robert. 2013. "Environmental Protection, Rare Disasters, and Discount Rates." Unpublished.

Dietz, Simon. 2011. "High Impact, Low Probability: An Empirical Analysis of Risk in the Economics of Climate Change." Climatic Change 103 (3): 519-41.

-Greenstone, Michael, Elizabeth Kopits, and Ann Wolverton. 2013. "Developing a Social Cost of Carbon for US Regulatory Analysis: A Methodology and Interpretation." Review of Environmental Economics and Policy 7 (1): 23-46.

Litterman, Robert. 2013. "What is the Right Price for Carbon Emissions?" Regulation 36 (2): $38-43$.

-Millner, Antony. 2013. "On Welfare Frameworks and Catastrophic Climate Risks." Journal of Environmental Economics and Management 65 (2): 310-25.

Pindyck, Robert S. 2013. "Climate Change Policy: What Do the Models Tell Us?" Journal of Economic Literature 51 (3): 860-72.

-Weitzman, Martin L. 2009. "On Modeling and Interpreting the Economics of Climate Change." Review of Economics and Statistics 91 (1): 1-19.

-Weitzman, Martin L. 2011. "Fat-Tailed Uncertainty in the Economics of Catastrophic Climate Change." Review of Environmental Economics and Policy 5 (2): 275-92. 